5 Mason DG, Bingham RM. The laryngeal mask airway in children. Anaesthesia 1990; 45: 760-3.

6 Collier $C$. A hazard with the laryngeal mask airway (Letter). Anaesth Intensive Care 1991; 19: 301.

7 Silk $J M$, Hill $H M$, Calder I. Difficult intubation and the laryngeal mask. Eur J Anaesth 1991; S4: 47-51.

8 Nandi PR, Charlesworth CH, Taylor SJ, Nunn JF, Dore $C J$. Effect of general anaesthesia in the pharynx. $\mathrm{Br} \mathrm{J}$ Anaesth 1991; 66: 157-62.

9 Sivarajan $M$, Fink $R$. The position and the state of the larynx during general anesthesia and muscle paralysis. Anesthesiology 1990; 72: 439-42.

\section{The laryngeal mask airway in awake patients}

To the Editor:

We read with interest the report by Williams and Bailey on the use of the laryngeal mask airway (LMA) in an awake patient for the management of failed oral fibreoptic intubation (Canadian Journal of Anaesthesia 1993; 40: 287). The authors state that this was the second case reported in which the LMA was inserted under topical anaesthesia and sedation. In fact, this technique has now been widely described and several authors have reported insertion of the LMA in awake volunteers or patients. ${ }^{1-5}$ Furthermore, we have reported the use of the LMA as an aid to awake diagnostic bronchoscopy in 50 patients with topical spray, a crico-thyroid puncture and sedation. ${ }^{6}$ More recently, Asai has described the use of the LMA in awake patients as an aid to both rapid sequence induction and awake intubation. ${ }^{7}$ There is indirect evidence that LMA insertion is not compromised in the patient who is difficult to intubate. ${ }^{8,9}$

The LMA can help solve the problem of the anaesthetised patient whose trachea is impossible to intubate when it can be used either as a substitute airway or as an aid to intubation. ${ }^{10}$ The report of Williams and Bailey adds further weight to an increasing body of evidence suggesting that insertion of the LMA in awake patients is easy to perform, acceptable to the patient and provides both an adequate airway and good conditions for intubation via the LMA. A particular advantage of this technique is the opportunity to induce anaesthesia before trachea intubation once a clear airway has been established with the LMA. We feel that the role of the LMA in the management of the difficult airway should probably be extended, although confirmation of this awaits the results of controlled trials. Meanwhile we would like to suggest, for an experienced operator, to consider awake insertion of the LMA as a first line approach to aid in- tubation where difficulty is anticipated in the patient not at risk of aspiration.

J. Brimacombe MB ChB FRCA

A. Berry MB ChB FRCA

Department of Anaesthesia and Intensive Care

Cairns Base Hospital

The Esplanade

Cairns 4870

Australia

\section{REFERENCES}

I McCrirrick A, Ramage DT, Pracilio JA, Hickman JA. Experience with the laryngeal mask airway in two hundred patients. Anaesth Intensive Care 1991; 19: 256-60.

2 Maltby $J R$. The laryngeal mask airway. Anaesthesiology Reviews 1991; 18: 55-7.

3 Sellers WFS, Edwards RJ. Awake intubation with Brain laryngeal mask. Anaesth Intensive Care 1991; 19: 473.

4 Ferguson $C$, Herdman $M$, Evans $K$, Hayes $M$, Cole PV. Flow resistance of the laryngeal mask in awake subjects. $\mathrm{Br}$ J Anaesth 1991; 66: 400P.

5 Brain AIJ. The development of the laryngeal mask - a brief history of the invention, early clinical studies and experimental work from which the laryngeal mask evolved. Eur J Anaesthesiol 1991; 4: 5-17.

6 Brimacombe J, Newell S, Swainston R, Thompson J. A potential new technique for awake fibreoptic bronchoscopy - use of the laryngeal mask airway. Med J Aust 1992; 156 : 876-7.

7 Asai $T$. Use of the laryngeal mask for tracheal intubation in patients at increased risk of aspiration of gastric contents. Anesthesiology 1992; 77: 1029-30.

8 Mahiou P, Narchi P, Veyrac $P$, Germond $M$, Gory $G$, Bazin $G$. Is laryngeal mask easy to use in case of difficult intubation? Anesthesiology 1992; 77: A1228.

9 Brimacombe J, Berry A. Mallampatti classification and laryngeal mask insertion. Anaesthesia 1993; 48: 347.

10 Silk JM, Hill HM, Calder I. Difficult intubation and the laryngeal mask. Eur J Anaesthesiol 1991; 4: 47-51.

\section{The Combitube oesophageal-tracheal double lumen airway for difficult intubation}

To the Editor:

The oesophageal-tracheal double lumen airway has stemmed from the concept of the oesophageal obturator airway. ${ }^{1,2}$ The ASA task force on the management of 